\title{
Study of Correlation Between Glycated Hemoglobin (Hba1c) and Serum Lipid Profile in Type 2 Diabetic Patients
}

\author{
Shrestha A
}

\section{ABSTRACT}

Introduction: Diabetic mellitus is a chronic metabolic disease characterized by hyperglycemia. Type 2 diabetes mellitus accounts for more than $90 \%$ of cases worldwide. Elevated $\mathrm{HbA1c}$ and dyslipidemia proportionately increases the risk of development of cardiovascular disease (CVD) which is the major cause of morbidity and mortality worldwide. Aim : To Study the correlation between glycated hemoglobin ( $\mathrm{HbA1c}$ ) and serum lipid profile in type 2 diabetic patients. Methods: This is a hospital based cross sectional study conducted at Nepalgunj medical college teaching hospital, which included 104 type 2 diabetic patients (54 males and 50 females).Venous blood samples were collected from all patients and serum was used for analyzing HbA1c, lipid profile panel and fasting blood glucose (FBG). DM was defined as per American diabetic association (ADA) criteria. Dyslipidemia was defined as per the National Cholesterol Education Program (NCEP) Adult Treatment Panel (ATP) III Guidelines. The data were analyzed using standard statistical methods, including SPSS 21. Results : Abnormal lipid parameters were demonstrated with increased Total Chloseterol (TC), Triglyceride (TG), Low density lipoprotein (LDL),Very low density lipoprotein (VLDL) and low High density lipoprotein (HDL) suggestive of dyslipidemia.HbA1c showed direct and significant correlation with TC,LDL,TG and VLDL. Patients with $\mathrm{HbA} 1 \mathrm{c}>7.0 \%$ had a significantly higher value of TC, LDL, TG and VLDL as compared to patients with $\mathrm{HbA1c} \leq 7.0 \%$. However, the significant difference in value of HDL-C was not found between two groups. Conclusion: Due to the strong correlation with lipid profile, HbA1c could be the ideal marker for predicting dyslipidemia in type $2 \mathrm{DM}$. Patients with higher HbA1c value and dyslipidemia should be considered as a very high risk group for CVD.

Keywords: Dyslipidemia, HbA1c, Type 2 Diabetes mellitus

Author:

Dr. Anil Shrestha

\section{Address for Correspondence:}

\author{
Dr. Anil Shrestha \\ Department of Internal Medicine \\ Nepalgunj Medical College and Teaching Hospital \\ Kohalpur, Banke, Nepal \\ Email: shtani4@gmail.com
}

\section{INTRODUCTION}

Diabetes Mellitus (DM) refers to a group of common metabolic disorder that share the phenotype of hyperglycemia. The factors contributing to hyperglycemia are reduced insulin secretion, decreased glucose utilization and increased glucose production. ${ }^{1}$ DM causes about $5 \%$ of all deaths globally each year. The chronic hyperglycemia of DM is associated with long term dysfunction and failure of various organs like kidney, nerves, eye, heart and blood vessels. 50\% of people with diabetes die of cardiovascular disease. ${ }^{2,3}$ With an increasing incidence worldwide, DM will be leading cause of morbidity and mortality for the forseable future.

Type 2 diabetic patients may have several forms of dyslipidemia, most common pattern being hypertriglyceridemia and reduced HDL cholesterol levels which greatly increase the risk of cardiovascular disease (CVD) compared with people without DM. An early investigations to correct dyslipidemia has shown to reduce cardiovascular events and morbidity in individual with DM. ${ }^{4,5}$
Measurement of glycated hemoglobin ( $\mathrm{HbA} 1 \mathrm{c})$ is the standard method for assuring long term glycemic control and it reflects the glycemic history of previous 2-3 months. ${ }^{1}$ Classical risk factors as well as elevated $\mathrm{HbA} 1 \mathrm{c}$ has now been regarded as an important risk factor for CVD in individuals with or without diabetes. CVD risk increases by $18 \%$ for each $1 \%$ increase in absolute $\mathrm{HbA1c}$ value in diabetic population ${ }^{6}$ where as reduction of $\mathrm{HbA} 1 \mathrm{c}$ by $0.2 \%$ reduces cardiovascular mortality by $10 \% .^{7}$ Even within normal range of $\mathrm{HbA} 1 \mathrm{c}$, positive relationship between $\mathrm{HbA} 1 \mathrm{c}$ and CVD has been demonstrated in non diabetic cases. ${ }^{8}$ The aim of this study was to find out the relationship between $\mathrm{HbA} 1 \mathrm{c}$ and serum lipid profile in type 2 DM in Nepalese population.

\section{METHODS}

This is a Hospital based cross sectional study conducted at Nepalgunj Medical College Teaching Hospital , Kohalpur,Nepal, Department of Internal Medicine from December 2019 to June 2020.Total of 104 type 2 diabetic patients (54 males and 
50 females) attending Medicine OPD and admitted at medicine wards were included in the study. The study was approved by Institutional Review Committee (IRC) and informed consent was obtained from all patients. Cases were enrolled into the study after meeting inclusion and exclusion criteria.

Inclusion criteria : Age $\geq 30 y$ rs

Both male and female patients

Known case of type 2 DM under medication or newly diagnosed type $2 \mathrm{DM}$

Exclusion criteria : known case of type $1 \mathrm{DM}$

Hypothyroidism, chronic renal failure

Patients already on lipid lowering drugs

Venous blood samples were collected from all patients after at least 8 hours fasting. The serum was used for analyzing fasting blood glucose (FBG), Lipid profile panel -TC,TG,HDL-C by using fully automated biochemistry analyzer,Mindray BS380/ BS230(Germany) and indirect LDL-C was calculated using Fridewald's formula. HbA1c was estimated by using automatic BIORAD D10 (USA). DM was defined as per ADA criteria . NCEP ATP Panel III guideline was referred for serum lipid reference level. Hypercholesterolemia is defined as TC $>200 \mathrm{mg} / \mathrm{dl}$, high LDL-C when value $>100 \mathrm{mg} / \mathrm{dl}$, Hypertriglyceridemia as TG $>150 \mathrm{mg} / \mathrm{dl}$ and Low HDL-C when value $<40 \mathrm{mg} / \mathrm{dl}^{1}{ }^{1}$ Dyslipidemia was defined by presence of one or more than one abnormal serum lipid concentration. The data were analyzed using standard statistical methods including SPSS 21. Quantitative data were expressed as mean and standard deviation (SD). Statistical tool used was student's t-test. P value less than 0.05 was considerd to be statistically significant.

\section{RESULTS}

A total of 104 type 2 diabetic patients were enrolled in the study, 54 were males and 50 were females.The mean age of male and female patients were $56.26 \pm 11.24$ and $54.34 \pm 10.79$ respectively. Although mean value of lipid profile, $\mathrm{HbA1c}$ and FBG were slightly higher in females than males, these differences were statistically non significant (Table I).

\begin{tabular}{|cccc|}
\hline Parameter & Male $(n=54)$ Mean \pm SD & Female $(n=50)$ Mean \pm SD & P Value \\
\hline Age (Years) & $56.26 \pm 11.24$ & $54.34 \pm 10.79$ & \\
\hline TC & $181.99 \pm 32.79$ & $187.12 \pm 25$ & 0.374 \\
\hline TG & $174.07 \pm 50.39$ & $181.06 \pm 101.22$ & 0.653 \\
\hline LDL & $103.89 \pm 25.03$ & $107.66 \pm 20.99$ & 0.409 \\
\hline HDL & $43.20 \pm 6.69$ & $45.31 \pm 8.96$ & 0.176 \\
\hline VLDL & $34.80 \pm 10.08$ & $35.92 \pm 20.09$ & 0.717 \\
\hline FBS & $149.48 \pm 40.75$ & $153.29 \pm 41.90$ & 0.639 \\
\hline HbA1c & $9.05 \pm 2.45$ & $9.34 \pm 2.73$ & 0.579 \\
\hline
\end{tabular}

Table I: Age and Biochemical parameters of male and female type 2diabetic patients

Hypercholesterolemia was found in 39 patients (37.5\%), increased LDL-C in 58(55.8\%) patients, hypertriglyceredemia and increased VLDL-C in 62(59.6\%) patients and decreased HDL-C 19(18.3\%) patients as shown in table II.

\begin{tabular}{|cccccc|}
\hline & TC & LDL & TG & VLDL & HDL \\
\hline Male & 17 & 28 & 37 & 37 & 12 \\
& $(43.6 \%)$ & $(48.3 \%)$ & $(59.7 \%)$ & $(59.7 \%)$ & $(63.2 \%)$ \\
\hline \multirow{2}{*}{ Female } & 22 & 30 & 25 & 25 & 7 \\
& $(56.4 \%)$ & $(51.7 \%)$ & $(40.3 \%)$ & $(40.3 \%)$ & $(36.8 \%)$ \\
\hline \multirow{2}{*}{ Total } & $\mathbf{3 9}$ & $\mathbf{5 8}$ & $\mathbf{6 2}$ & $\mathbf{6 2}$ & $\mathbf{1 9}$ \\
& $\mathbf{( 3 7 . 5 \% )}$ & $\mathbf{( 5 5 . 8 \% )}$ & $\mathbf{( 5 9 . 6 \% )}$ & $\mathbf{( 5 9 . 6 \% )}$ & $\mathbf{( 1 8 . 3 \% )}$ \\
\hline
\end{tabular}

Table II : Abnormal lipids parameters in type 2 diabetic patients

According to glycemic status, patients were classified into two groups. HbA1c $\leq 7.0 \%$ was considered first group and $\mathrm{HbA} 1 \mathrm{C}$ $>7.0 \%$ was considered second group. Patients with $\mathrm{HbA1c}>$ $7 \%$ had statistically significant higher value of $\mathrm{TC}(\mathrm{P}=<0.001)$, TG $(P=0.028), \operatorname{LDL}-C(P=<0.001), \operatorname{VLDL}(P=0.021), F B G(P=<$ 0.001 ) as compared to the patients with $\mathrm{HbA1c} \leq 7.0 \%$ where as HDL-C showed negative correlation with $\mathrm{HbA1c}$ though it was statistically non significant ( table III).

\begin{tabular}{cccc|} 
Parameter & \multicolumn{2}{c}{ Glycated Haemoglobin $($ HbA1c) } & P Value \\
& \multicolumn{1}{c}{$\mathbf{7 \%}(\mathbf{n}=\mathbf{3 5})$} & $>\mathbf{7} \%(\mathbf{n}=\mathbf{6 9})$ & \\
\hline TC & $168.62 \pm 36.45$ & $192.50 \pm 20.98$ & $<0.001^{*}$ \\
\hline TG & $153.71 \pm 47.88$ & $189.45 \pm 88.31$ & $0.028^{*}$ \\
\hline LDL & $92.59 \pm 26.72$ & $112.35 \pm 17.92$ & $<0.001^{*}$ \\
\hline HDL & $45.57 \pm 9.26$ & $43.53 \pm 7.07$ & 0.213 \\
\hline VLDL & $30.39 \pm 8.95$ & $37.84 \pm 17.65$ & $0.021^{*}$ \\
\hline FBS & $118.14 \pm 18.42$ & $168.14 \pm 39.26$ & $<0.001^{*}$ \\
\hline
\end{tabular}

Table III : Biochemical parameters categorized by glycemic control (HbA1c)

\section{DISCUSSION}

The present study evaluated the pattern of lipid profile parameters in type 2 diabetic patients and its correlation with HbA1c. This study shows high prevalence of hypertriglyceredemia, high LDL- C, hypercholesterolemia and low HDL-C levels in type 2 diabetic patients. These are well known risk factors of cardiovascular diseases. Insulin affects liver appolipoprotein production. It regulates the enzymatic activity of lipoprotein lipase (LPL) and cholesterol ester transport protein. All these factor are likely cause of dyslipidemia in DM. ${ }^{9}$ In this study, most significant disorder in lipid profile was hypertriglyceredemia. Similar finding was shown by Regmi $P$ et $\mathrm{a}^{10}$ and Mahato RV et al. ${ }^{11}$

This study shows highly significant correlation between $\mathrm{HbA1c}$ and FBG which is similar to studies done by Ito $c$ et al ${ }^{12}$, ko GT et $\mathrm{a}^{13}$ and Rosediani et al. ${ }^{14}$ This study also found significant correlation between $\mathrm{HbA} 1 \mathrm{c}$ and TC, LDL- C as reported by $\mathrm{Er}$ ciyas $\mathrm{F}$ et $\mathrm{al}{ }^{15}$, Anderson GE et $\mathrm{al}^{16}$, Ohta T et $\mathrm{al}^{17}$ in their studies.

The diabetes complications and control trial (DCCT) considered $\mathrm{HbA1C}$ as the gold standard of glycemic control. The target $\mathrm{HbA1c}$ value for reducing cardiovascular complication was 
Shrestha A : Study of Correlation Between Glycated Hemoglobin (Hba1c) and Serum Lipid Profile in Type 2 Diabetic Patients

$\leq 7.0 \%$. In this study, we classified diabetic patients in 2 groups as per the $\mathrm{HbA} 1 \mathrm{c}$ cut off of $7.0 \%$. Th patients with $\mathrm{HbA} 1 \mathrm{C}$ value $>7.0 \%$ showed significant increase in TC, LDL $-C$, TG and VLDL without any significant change in HDL-C in comparision to patients with $\mathrm{HbA} 1 \mathrm{c} \leq 7.0 \%$. Khan $\mathrm{HA}$ et $\mathrm{al}^{18}$ showed the impact of glycemic control on various lipid parameters. Though there was no signifant differences in LDL-C with regard to glycemic control, alterations in other lipid parameters were statistically significant. Thus, this study suggests that severity of dyslipidemia increases with higher $\mathrm{HbA} 1 \mathrm{c}$ value and diabetic patients with increased $\mathrm{HbA1c}$ and dyslipidemia should be considered as very high risk group for cardiovascular disease (CVD). Therefore, we should focus on improving glycemic control which can essentially reduce the risk of cardiovascular events in diabetics. ${ }^{19}$ It has been considered that reduction in HbA1c level by $0.2 \%$ could lower the cardiovascular mortality by $10 \% .^{7}$

\section{LIMITATION}

Though menopausal status affects the lipid profile, it was not considered in this study. Non diabetic controls would provide better comparison of lipid profile which should be added in future studies. In addition to this, sample size also might have been inadequate for drawing the definite conclusion.

\section{CONCLUSION}

This study shows that type 2 DM has significant relation with dyslipidemia. Along with blood glucose, frequent monitoring of lipid profile is equally important for the best care of type 2 diabetic patients and to decrease the risk of cardiovascular events. $\mathrm{HbA} 1 \mathrm{C}$ is the gold standard tool for the assessment of glycemic control and it could be the ideal marker for identifying dyslipidemia in type 2 DM.

\section{REFERENCES}

1. Powers AC .Diabetes Mellitus. In: Fauci AS, Kasper DL, Hauser SL, Longo DL, Jamenson Jl, Loscalzo J, editors. Harrison's principles of internal medicine. 18 th edition. New York: McGraw Hill; 2012, p 2968-92.

2. Diabtes.http://.who.int/mediacentre/factsheets/fs312/en/ index.html (Updated on November 2009).

3. Glycosylaed Haemoglobin, HbA1C.hptt:// clinlabnavi-gator.com/ test-interpretations/haemoglobin-a1c.html? letter=h (Updated on 18 June 2010).

4. Haffner SM, Lehto S, Ronnemaa T, Pyorala K, Laakso M. Mortality from coronary heart disease in subjects with type 2 diabetes and in nondiabetic subjects with and without prior myocardial infarction. N Engl J Med 1998; 339: 229-234

5. Windler $\mathrm{E}$. What is the consequence of an abnormal lipid profile in patients with type 2 diabetes or the metabolic syndrome? Atheroscler Suppl 2005;6: 11-14.
6. Selvin E, Marinopoulos S, Berkenblit G, Rami T, Brancati FL, Powe NR, et al. Meta-analysis: glycosy-lated hemoglobin and cardiovascular disease in diabetes mellitus. Ann Intern Med 2004; 14: 421-431.

7. Baranwal JK, Maskey R, Majhi S, Lamsal M, Baaral N. Association between level of $\mathrm{HbA1C}$ and lipid profile in T2DM patients attending diabetic opd at BPKIHS . Health Renaissance. 2015 :13(3):16-23. http://doi.org/10.3126/jcmc.v7il.17365

8. Khaw KT, Wareham N, Bingham S, Luben R, Welch A and Day N. Association of hemoglobin A1c with car-diovascular disease and mortality in adults: the European Prospective Investigation into Cancer in Norfolk. Ann Intern Med 2004; 141: 413-420.

9. Goldberg IJ. Lipoprotein lipase and lipolysis: central roles in lipoprotein metabolism and atherogenesis. J Lipid Res 1996; 37: 693-707.

10. Regmi P, Gyawali P, Shrestha R, Sigdel M, Mehta KD, Majhi S. Pattern of Dyslipidemia in Type 2 Diabetic Subjects in Eastern Nepal. JNAMLS 2009; 10: 11-13.

11. Mahato RV, Gyawali P, Raut PP, Regmi P, Singh KP, Pandeya DR Association between glycemic control and serum lipid profile in type 2 diabetic patients: Glycated hemoglobin as dual biomarker. Biomedical research $2011: 22(3):$ 375-380

12. Ito C, Maeda R, Ishida S, Sasaki H, Harada H. Correlation among fasting plasma glucose, two-hour plasma glucose levels in OGTT and HbA1c. Diabetes Res Clin Pract 2000; 50: 225-230.

13. Ko GT, Chan JC, Woo J, Lau E, Yeung VT, Chow CC, et al. Glycated hemoglobin and cardiovascular risk fac-tors in Chinese subjects with normal glucose tolerance. Diabet Med 1998;15: 573-578.

14. Rosediani M, Azidah AK, Mafauzy M. Correlation between fasting plasma glucose, post prandial glucose and glycated haemoglobin and fructosamine. Med J Malaysia 2006; 61: 6771.

15. Erciyas F, Taneli F, Arslan B, Uslu Y. Glycemic con-trol, oxidative stress and lipid profile in children with type 1 Diabetes Mellitus. Arch Med Res 2004; 35:134-140.

16. Andersen GE, Christiansen JS, Mortensen HB, Christiansen KM, Predersen-Bjerguard L, Kastrup KW, et al. Plasma lipid and lipoprotein in type 1 diabetic children and adolescent in relation to metabolic regulation,obesity and genetic hyperlipoprotenimia. Actu paediator Scand 1983; 72: 361-365.

17. Ohta T, Nishiyama S, Nakamura T, Saku K, Maung KK, Matsuda I. Predominance of large low density lipoprotein particles and lower fractional esterification rate of cholesterol in high density lipoprotein in children with insulin-dependent diabetes mellitus. Eur J Pediatr 1998; 157: 276-281.

18. Khan HA, Sobki SH, Khan SA. Association between glycaemic control and serum lipids profile in type 2 diabetic patients: HbA1c predicts dyslipidaemia. Clin Exp Med 2007; 7: 24-29.

19. Selvin E, Wattanakit K, Steffes MW, Coresh J, Sharrett AR. HbA1C and peripheral arterial disease in diabetes: the Atherosclerosis Risk in Communities study. Diabetes Care 2006; 29: 877-882. 